\title{
Scaling Up Programs: Reflections on the Importance of Process Evaluation
}

\author{
Andria Parrott \\ University of San Diego \\ Joanne Genova Carman \\ University of North Carolina-Charlotte
}

\begin{abstract}
For more than a decade, policy makers and funding agencies have been focused on identifying innovative and successful programs and bringing them to scale. Evaluators play an important role in these scaling efforts by helping to document what works and by monitoring program implementation. They can also monitor the replication of taking innovative programs to scale. In this research and practice note, we reflect on our evaluation experiences with a public-private partnership designed to scale up a health and wellness program within a large, urban school district at ten elementary schools. In doing so, we highlight the importance of conducting a process evaluation at the beginning of the program to ensure that the program is being implemented as intended. We also describe how these early evaluation findings helped to improve the program during its second year.
\end{abstract}

Keywords: dosage, fidelity, participant responsiveness, process evaluation, quality, scaling

Resumé : Depuis plus de dix ans, les décideurs et les organismes de financement tentent d'identifier des programmes novateurs et efficaces et de les adapter à des contextes plus larges. Les évaluateurs jouent un rôle important dans cette démarche, puisqu'ils peuvent documenter les composantes qui fonctionnent bien et assurer le suivi de la mise en cuvre des programmes. Ils peuvent aussi assurer le suivi du transfert de programmes novateurs à d'autres contextes. Dans cette note sur la pratique, nous analysons un cas vécu, où nous cherchions à implanter un programme de santé et bien-être dans 10 écoles primaires d'un vaste district scolaire en milieu urbain. Nos résultats soulignent l'importance d'effectuer une évaluation de la mise en ouvre au début du programme pour s'assurer qu'elle se déroule comme prévu. Nous décrivons aussi la contribution des résultats d'évaluation à l'amélioration le programme au cours de sa deuxième année d'implantation.

Corresponding author: Joanne Genova Carman, UNC Charlotte, Department of Political Science \& Public Administration, 9201 University City Blvd., Charlotte, NC, 28223-0001, USA; jgcarman@uncc.edu 
Mots clés : Dosage, fidélité, réaction des participants, évaluation de la mise en œuvre, qualité, transférabilité

As the focus on outcomes, evidence-based practice, and scaling up programs that work continues to grow, it is important to remember the benefits of conducting a process evaluation. These evaluations are especially important in public schools today as poor performance, diminished funds, and increased accountability for academic achievement restrict their ability to offer extracurricular opportunities that may be worthwhile to students. In this research and practice note, we describe how the findings from a process evaluation of an elementary school-based health and wellness program yielded valuable insights that helped to greatly improve efforts to scale up the program across a large, urban school district.

\section{CONTEXT FOR EVALUATION PRACTICE}

For more than a decade, policy makers and funding agencies have spent a considerable amount of time and energy focusing on identifying successful programs and bringing them to scale. Riddell and Moore (2015) describe three types of scaling: scaling up to replicate innovative solutions; scaling out in an effort to reach greater numbers; and scaling deep in order to change culture and learning (p. 4). Evaluators play an important role in these scaling efforts. Not only do they help to document and identify what works, but they can also monitor the replication process of taking innovative programs to scale (Gove, Korda Poole, \& Piper, 2017; Westley, Antadze, Riddell, Robinson, \& Geobey, 2014).

\section{A health and wellness program}

In recent years, a small, but growing, number of schools have been implementing health and wellness programs, which typically incorporate yoga, movement, meditation, breathing, relaxation exercises, and other curricula designed to improve physical fitness, increase self-confidence and self-esteem, and decrease anxiety and stress among students (Ferreira-Vorkapic et al., 2015; Khalsa, Hickey-Schultz, Cohen, Steiner, \& Cope, 2012; Serwacki \& Cook-Cottone, 2012). Some evaluations of mindfulness practices with youth have been found to reduce stress, anxiety, and emotional and behavioral reactivity, and to improve self-awareness and sleep (Bootzin \& Stevens, 2005; Napoli, Krech, \& Holley, 2005; Semple, Reid, \& Miller, 2005; Wall, 2005). Other evaluations have found that the ability to manage oneself in stressful circumstances (self-regulation) contributes to school readiness and long-term academic success for youth (Graziano, Reavis, Keane, \& Calkins, 2007; Gumora \& Arsenio, 2002).

Building upon this growing body of research, in 2011 a private foundation began to develop a health and wellness curriculum for elementary schools that was designed to promote student physical health, mental health, and wellness. The curriculum involved providing students with a dedicated period during the school 
day for lessons on health and wellness. Schools partnering with this foundation hired one instructor to deliver the health and wellness curriculum to students in a dedicated space within the school. Students would arrive at the health and wellness classroom with their classmates twice weekly for a 40-minute lesson led by their health and wellness instructor. Teachers had that time to either join students for health and wellness or to attend to other preparatory matters back in their classroom.

Students began each health and wellness class learning various breathing strategies to apply to stressful situations encountered both in and outside of school. Next, yoga-based movements were introduced to enhance physical strength and flexibility. Each lesson concluded by practicing different focusing techniques designed to help students centre or re-engage in the learning environment, followed by a restful few moments of quiet time in a comfortable position, often with muted lighting and peaceful music. Over the course of several years, the foundation worked with different school districts to adopt, refine, and replicate the curriculum at various elementary schools and grade levels.

In the fall of 2014, the foundation partnered with a large urban school district in an effort to scale up the program and integrate it into 10 public elementary schools. The partnership between the school district and the foundation was a classic example of venture philanthropy, involving multi-year funding for innovative solutions for public policy problems, making investments into building the capacity of organizations, measuring outcomes, and scaling "what works" for greater impact (Bradach, 2010; Grossman, Appleby, \& Reimers, 2013). Through this partnership, the foundation was especially interested in implementing a program that would enhance the health and academic success of children attending schools in urban environments.

The foundation also funded the external evaluation of the program, which was intentionally designed to look at the process of the program with the purpose of improving program implementation to more effectively expand health and wellness programs to other schools within this large school district. ${ }^{1}$ For the process evaluation, data were gathered through pre- and post-surveys of upper-grade students; interviews with principals, health and wellness instructors, and district administrators; focus groups with teachers, health and wellness instructors, and parents; and observations of the health and wellness classrooms at the schools participating in the program. Surveys shared students' overall satisfaction with the program and if they felt the acquired knowledge helped them in other areas of life. Interviews and focus groups offered insight about participants' perception of the program's purpose, successes and challenges surrounding the program's presence on their school campus, and the ways in which stakeholders believed the program could be improved in subsequent years. An observation protocol was developed and used to track how lessons were delivered consistently across all schools with relation to classroom management, curricular pacing, instructional delivery, and other factors important to student learning. 
Observation, interview, focus group and survey data were collected across all participating schools in order to understand nuanced differences about how students, school leaders, staff as well as parents received the program within their school. Survey data were analyzed using SPSS software, all interview data were recorded and transcribed, and observational data were compiled by the evaluation team to ensure inter-rater reliability. All qualitative data were analyzed using a conventional content analysis, and triangulation of all data ensured the consistency of findings to effectively improve the program's delivery in subsequent years.

\section{USE OF THE PROCESS DATA}

Data that were collected throughout the first year were used to enhance the health and wellness program in a variety of ways. The evaluation team was asked to separately share findings with the district's leadership team, the foundation's leaders and support staff, school principals, and health and wellness instructors in order to initiate a collective dialogue around program improvement. Process data were used in four ways that proved especially useful in year two.

First, the data suggested program refinement would best be achieved if the district and foundation worked together to remedy the issues that had surfaced in year one. Incorporating a yoga and mindfulness-based wellness program in public schools was a unique experience, and both district and foundation stakeholders needed to call upon one another's expertise to devise solutions to new challenges. Performance reviews of health and wellness instructors, for example, were a new challenge for school leaders. They had experience reviewing the knowledge and skills of their classroom teachers, but reviewing a health and wellness instructor's aptitude was unfamiliar. Data from this evaluation showcased several nuanced situations of this nature, and school and district leaders learned to work collaboratively toward solutions in year two.

Second, the process evaluation was able to show how students, parents, and teachers felt about the health and wellness program's presence on their school campus. Overall, the vast majority of the students reported that they liked the program. Parents shared comments about how their school's health and wellness program helped their child "improve physically and mentally," and teachers reported that they were pleased that students had learned strategies to calm themselves in stressful situations. Providing stakeholders with survey data and testimonials about the positive impact participants perceived the program was having on the health and well-being of students was encouraging, and district and foundation leaders were motivated to improve the program in year two as a result.

Third, though most participants found the program favorable in year one, data from the process evaluation found there was variability in quality of instruction across schools and a need to provide a more structured system to support the health and wellness instructors' success. Observation and interview data affirmed differences in health and wellness instructors' abilities and experience in addition to the degree of educational support they were receiving at their school site. The data 
revealed that some instructors, for example, had a great deal of experience working with children but had never taught using a curriculum. Others had extensive backgrounds in health and wellness, but their experience in schools was limited. These differences affected the quality of instruction across schools, and presenting these data to school and district leaders showcased the need to provide structured, ongoing professional development opportunities to health and wellness instructors.

Finally, the variability in data collected across schools showcased a need to increase accountability in many aspects of the program in year two, both for health and wellness instructors and for school leaders. Many instructors in year one, for example, were found to be completing curricular lessons and units at a pace that suited them. Some lessons were expanded to incorporate additional objectives such as additional yoga poses or academic content, while other lessons were skipped all together. This left students across the ten schools learning different skills at different periods of time. Further showcasing the variability across schools, some school leaders required all participating students to consistently attend health and wellness while other school leaders permitted students to be pulled from health and wellness for academic tutorial sessions. Attendance was found to be sporadic, with variation in the scheduling of the classes, the amount of dedicated instructional time, and consistency in offering the classes at many participating schools. In sum, process data were used to showcase the variability of many programmatic factors across schools and to validate the need to hold schools and their health and wellness instructors to greater levels of accountability.

\section{IMPLICATIONS FROM THE PROCESS EVALUATION}

This systematic one-year process evaluation of the district's health and wellness program offered valuable insight to refine the program at each of the participating schools in year two, and additionally to scale up the program across the large, urban district in a more effective way. Implications that were especially valuable aligned with four of Durlak and DuPre's (2008) features of implementation (dosage, quality, fidelity, and participant responsiveness), providing an opportunity to share tangible, useful insights to district and foundation leaders as they strived to improve the health and wellness program outcomes for year two.

\section{Dosage}

By presenting district and foundation leaders with data that showed the variability in dosage in year one, policy changes were suggested to the schools for year two to ensure students were more consistently attending health and wellness class. Schools were required to submit their health and wellness schedules at the beginning of year two, ensuring that a minimum of two 40-minute health and wellness classes were provided to all participating students. Additionally throughout year two, health and wellness instructors completed a monthly foundation-administered survey to track students' instructional time. These two changes in year two improved dosage inconsistencies across all participating schools. 


\section{Quality}

After learning about the variation in quality across schools in year one, district and program leaders implemented three changes in year two to offer students a more meaningful health and wellness experience. First, instructors who were deemed ineffective were replaced with more effective instructors. Second, bimonthly professional development training sessions and one-on-one coaching for all health and wellness instructors were instituted covering concepts including classroom management, instructional planning and delivery, differentiated instruction, and more. Third, district and program leaders conducted regular classroom observations to ensure that the health and wellness curriculum was being implemented consistently and in a quality manner.

\section{Fidelity}

Given that the process evaluation identified a lack of fidelity in implementing the curriculum, district and program leaders implemented two changes in year two. First, program advocates required greater accountability from health and wellness instructors and increased their presence in schools as a result. Lesson objectives were visibly presented to all students and visitors who entered the health and wellness room. Thus, anyone observing a lesson could read what lesson was being taught and what students would learn during that class session. Second, the curriculum was modified to include pacing guides which ensured that lessons were being taught within the same time period across schools. This alignment allowed professional development sessions to be more meaningful to health and wellness instructors and resulted in greater fidelity of instruction across schools.

\section{Participant responsiveness}

Though participants were generally positive about the health and wellness program's presence on their school's campus, the improvements relating to the dosage, quality, and fidelity issues were positively received by teachers and parents, who were provided opportunities to observe and engage in health and wellness activities alongside the students. Observations of these changes suggested that they were well received by the students.

\section{IMPLICATIONS FOR PRACTICE}

While there continue to be pressures to document and measure the outcomes of programs, scale up successful programs, and conduct rigorous evaluations in order to contribute to the evidence pool of what works, process evaluation continues to be a valuable tool for evaluators. This is especially true in public schools with the rising demand for accountability and the depletion of available funds. By paying close attention to dosage, quality, fidelity, and participant responsiveness during the first year of the health and wellness program's replication, we were able to help the school district to improve the program during its second year. We hope 
that by sharing our experiences as evaluators in this research and practice note, we have showcased that while outcomes and other types of evaluations remain important, process evaluations make valuable contributions that help to improve program outcomes and the success of program replications.

\section{NOTE}

1. Though outcome and other evaluation data were collected as part of the external evaluation, the focus of this research and practice note is on the process evaluation.

\section{REFERENCES}

Bootzin, R. R., \& Stevens, S. J. (2005). Adolescents, substance abuse, and the treatment of insomnia and daytime sleepiness. Clinical Psychology Review, 25(5), 629-644. https:// doi.org/10.1016/j.cpr.2005.04.007. Medline:15953666

Bradach, J. (2010, Summer). Scaling impact. Stanford Social Innovation Review, 27-28.

Durlak, J. A., \& DuPre, E. P. (2008). Implementation matters: A review of research on the influence of implementation on program outcomes and the factors affecting implementation. American Journal of Community Psychology, 41(3-4), 327-350. https://doi. org/10.1007/s10464-008-9165-0. Medline:18322790

Ferreira-Vorkapic, C., Feitoza, J. M., Marchioro, M., Simões, J., Kozasa, E., \& Telles, S. (2015). Are there benefits from teaching yoga at schools? A systematic review of randomized control trials of yoga-based interventions. Evidence-Based Complementary and Alternative Medicine. https://doi.org/10.1155/2015/345835. Medline:26491461

Gove, A., Korda Poole, M., \& Piper, B. (2017). Designing for scale: Reflections on rolling out reading improvement in Kenya and Liberia. In A. Gove, A. Mora, \& P. McCardle (Eds.), Progress toward a literate world: Early reading interventions in low-income countries. New Directions for Child and Adolescent Development, 155, 77-95.

Graziano, P. A., Reavis, R. D., Keane, S. P., \& Calkins, S. D. (2007). The role of emotion regulation and children's early academic success. Journal of School Psychology, 45(1), 3-19. https://doi.org/10.1016/j.jsp.2006.09.002. Medline:21179384

Grossman, A., Appleby, S., \& Reimers, C. (2013, June). Venture philanthropy: Its evolution and its future. Harvard Business School Background Note, 313-111, 1-25.

Gumora, G., \& Arsenio, W. F. (2002). Emotionality, emotional regulation, and school performance in middle school children. Journal of School Psychology, 40(5), 395-413. https://doi.org/10.1016/S0022-4405(02)00108-5

Khalsa, S. B. S., Hickey-Schultz, L., Cohen, D., Steiner, N., \& Cope, S. (2012). Evaluation of the mental health benefits of yoga in a secondary school: A preliminary randomized controlled trial. Journal of Behavioral Health Services \& Research, 39(1), 80-90. https:// doi.org/10.1007/s11414-011-9249-8. Medline:21647811

Napoli, M., Krech, P. R., \& Holley, L. C. (2005). Mindfulness training for elementary school students: The attention academy. Journal of Applied School Psychology, 21(1), 99-125. https://doi.org/10.1300/J370v21n01_05 
Riddell, D., \& Moore, M.-L. (2015, October). Scaling out, scaling up, scaling deep: Advancing systemic social innovation and the learning processes to support it. Prepared for the J.W. McConnell Family Foundation and Tamarack Institute. Retrieved from https:// mcconnellfoundation.ca/wp-content/uploads/2017/08/ScalingOut_Nov27A_AV_ BrandedBleed.pdf

Semple, R. J., Reid, E. F. G., \& Miller, L. (2005). Treating anxiety with mindfulness: An open trial of mindfulness training for anxious children. Journal of Cognitive Psychotherapy, 19(4), 379-392. https://doi.org/10.1891/jcop.2005.19.4.379

Serwacki, M. L., \& Cook-Cottone, C. (2012). Yoga in schools: A systematic review of the literature. International Journal of Yoga Therapy, 22, 101-109. Medline:23070680

Wall, R. B. (2005). Tai Chi and mindfulness-based stress reduction in a Boston public middle school. Journal of Pediatric Health Care, 19(4), 230-237. https://doi.org/10.1016/j. pedhc.2005.02.006. Medline:16010262

Westley, F., Antadze, N., Riddell, D. J., Robinson, K., \& Geobey, S. (2014). Five configurations for scaling up social innovation: Case examples of nonprofit organizations from Canada. Journal of Applied Behavioral Science, 50(3), 234-260. https://doi. org/10.1177/0021886314532945

\section{AUTHOR INFORMATION}

Andria Parrott is a Research Scientist in the Center for Biobehavioral Health at Nationwide Children's Hospital and an Adjunct Professor in the Department of Learning and Teaching at the University of San Diego.

Joanne Genova Carman is an Associate Professor in the Department of Political Science and Public Administration at the University of North Carolina at Charlotte. 